\author{
TURNING THE SUPER TANKER: \\ BEYOND ETHNOGRAPHY AND INTO COLLABORATIVE LEARNING \\ APPROACHES TO URBAN ENVIRONMENTAL MANAGEMENT
}

Kathryn Scott and Alison Greenaway

\begin{abstract}
This paper reflects on the place of ethnography in collaborative learning in the context of urban environmental management. The Low Impact Urban Design and Development (LIUDD) research programme is aimed at facilitating the uptake and implementation of low-impact principles, with a focus on improved approaches to storm-water management. Collaborative learning approaches include the use of case studies, learning groups and a web-based database. Place-based case studies are intended to showcase some examples of LIUDD and develop forums for refining research questions and developing innovative solutions. Ethnographic research approaches fit well with the process of collaborative learning, helping to understand how stakeholder groups think about, evaluate, control and manage land and other resources. Organising and presenting this information in accessible formats, providing opportunities for stakeholders to reflect on and learn from each others' practices and experiences, and facilitating critical dialogue aimed at transformative change are key aspects of the approach.
\end{abstract}

This article reflects on the place of ethnography in collaborative learning and multi-stakeholder participatory research. What is possible when we move 'beyond ethnography' as a research methodology and seek to facilitate learning and transformative change? This reflection draws on current work we are undertaking in the Low Impact Urban Design and Development (LIUDD) research programme. This programme, based at Landcare Research, aims to increase support for low environmental impact storm-water management.

Storm-water management is commonly considered a technical 'hard' engineering issue, the domain of experts. However, as an aspect of urban environmental management increasingly driven by integrated catchment approaches, 
'low environmental impact' approaches to storm-water management are being developed and implemented. These include a move towards more 'soft' technologies such as limiting impervious surfaces and earthworks, enhancing biodiversity and revegetation. Additionally, on-site devices such as rain gardens and swales and riparian planting involve purpose-built planted areas to slow water flows and filter pollutants before storm-water is discharged to the sea. Storm-water management, under this model, becomes the responsibility of a much broader range of people within local authorities, the development industry, landowners and community groups.

However, changing the way storm-water management and urban environmental management in general is carried out has been likened to 'turning a super tanker round' - alluding to the multiple constraints on implementing low-impact approaches. These constraints include a range of technical, ecological, economic, regulatory, and social issues that affect the way urban environmental management takes place. A range of research approaches are therefore called for, and collaborative learning approaches (using ethnographic methods) contribute to this process.

The LIUDD programme seeks to assess and improve the technical, ecological and economic efficiency of 'low impact' approaches to storm-water management. Collaborative learning approaches include the use of case studies, learning groups, and a web-based database. Place-based case studies are intended to showcase some examples of LIUDD, with a focus on organizational change and planning processes, lessons learnt and challenges encountered. The initial emphasis is on building relationships and getting a flow of knowledge and experience between scientists and industry and governance sectors. The learning approach is as much one for scientists as it is for other stakeholders. Key questions include: What is working? Why? Why not? How is change occurring?

This article briefly examines the emergence of environmental anthropology, and then explores the links between ethnographic and collaborative learning approaches. Collaborative learning is considered as a research process that moves beyond conventional 'buy-in' approaches to considering urban environmental management as materialized and shaped by social values, norms and practices. We then provide an overview of the LIUDD programme and reflect on some of the barriers to implementation of LIUDD in the views of people in industry and governance positions. This analysis of barriers to implementation and the context within which development is taking place provides the basis upon which we are now developing forums for critical reflec- 
tion and action on policies and practices related to LIUDD. The anthropologist is therefore moving 'beyond ethnography' and into developing opportunities for collaborative learning and improved urban environmental management.

\section{ENVIRONMENTAL ANTHROPOLOGY}

Environmental anthropology has at its core the analysis of human-environment relationships, involving an exploration of the different ways that cultural groups think about, value, manage and shape the environment (Head, Trigger \& Woodward, 2004). Though 'environmental anthropology' as a term has only emerged in the last decade (Mulcock, Pocock, and Toussaint, 2005), the study of human interaction with the environment has long been central to anthropology. The term encompasses the positivist and interpretive approaches of the 1960s and 1970s, and the more constructivist approaches of the last decade. Studies of environmental justice (Johnston, 1994), environmentalism and environmental movements (e.g. Brosius, 1999), and contestation over resource management (e.g. Scott, Park and Cocklin, 200o) are also expanding fields within environmental anthropology, giving voice to the ways the environment is constructed, represented, claimed, and contested. A common theme in much of this work is the notion that cultural identity and meaning are created through engagements with the physical environment, and at the same time continually mould and shape that environment (Mulcock et al., 2005, Strang, 2005).

LINKING ETHNOGRAPHY WITH COLLABORATIVE LEARNING APPROACHES

Environmental anthropologists have the much-needed capacity to document and interpret the taken-for-granted cultural values and practices that can have significant and often hidden implications for environmental management at every level (Mulcock et al., 2005: 288).

Current environmental problems are complex and interconnected, and have developed over many years, with much remaining unknown and contested about these conditions. Environmental issues have long been considered the domain of experts, and traditional scientific approaches have focused on problem solving and technology transfer (Greenaway et al 2006). Environmental management, increasingly devolved to regional and local scales, requires decision making amidst complexity and uncertainty. As Austin (2004) states, this creates major challenges: 
National and international discourses of need, threats, and lack of alternatives, coupled with silence about local impacts of development policies, create challenges for those trying to understand human-environment interactions and address environmental problems. However, none of us - indigenous leaders, peasants, urban dwellers, scientists, or religious prophets - have traditions that instruct us how to meet these challenges (2004:420).

Austin advocates the development of local-level partnerships that 'recognize and support community ownership of the problems, definitions, and paths for improvement' (2004:420), with the 'explicit purpose of integrating learning and social change and fostering civic participation' (2004:421). Collaborative learning approaches to science acknowledge the need to engage stakeholders at the outset in order to ensure relevancy and applicability of the research and to facilitate a two-way learning process.

A collaborative learning approach provides a forum for multiple stakeholders to share and gain benefits from each others' learnings and successes. Ideally this involves a cycle of problem identification, action planning, modelling the system as a whole, monitoring, critical reflection, redefining the problem, attempting new actions, and so on (Allen, et al., 1998, Austin, 2004, Keen, Brown, and Dyball, 2005, Stringer, 1999, van Roon, Greenaway, Dixon and Eason, 2006).

Ethnographic approaches are well suited to a collaborative learning framework that seeks to facilitate a process of learning, experimentation and reorganization to address environmental issues, involving stakeholders in a process of reflective practice and reciprocal learning (Austin, 2004, Wilhite, 2005). As a starting point, identifying the key stakeholders, building relationships, developing an understanding of the issues, dynamics, perceptions, experiences and aspirations of stakeholders are key. As in ethnographic research, the emphasis here is on participation and process, rather than data gathering or fact finding.

The use of multiple methods, a foundation for the recognised validity of ethnographic research (Agar, 1996), employs tools useful to the learning endeavour. Interviews, focus groups, case studies, and participant observation provide the basis to explore the dynamics, issues and concerns of the different stakeholders, identifying similarities and differences, strengths and weaknesses. Participant observation, the hallmark of ethnography, is essentially based on a learning approach whereby the participants are the experts (Ellen, 
1984, Bernard, 1988), the researcher the learner. Ethnography tends to focus on the locally specific, the "[f]ine grained observations, narratives from everyday life, and testimonies in the voice of otherwise anonymous subjects' (Marcus, 2005: 679). From there, these detailed data are situated within the broader social, economic and political context, and can be compared and contrasted with other contexts.

It is now commonly acknowledged that anthropologists, as 'cultural translators' drawing upon ethnographic research, are able to bring about engagement in relation to environmental issues (Head et al., 2004). Anthropologists can facilitate critical dialogue by organizing and presenting information in formats that are accessible to the different stakeholders (Austin, 2004, Strang, 2005). The anthropologist can identify the points of common interest ('we all want clean beaches') and reflect this to participants, identifying opportunities for working together.

Critical reflection is also a key aspect of both ethnography and collaborative learning, strengthening the ability to refine research questions and to influence the design of research experiments. Anthropologists are accustomed to reflecting critically on their own position as a researcher, recognising research as 'action' and the responsibilities that brings. Anthropologists also recognise the political agency of actors and the necessity to avoid essentialist portrayals of cultural perspectives (Brosius, 1999). It is particularly important not to frame groups of people with fixed values and perspectives in the context of urban environmental management as these can change over time and according to circumstances. This is, in part, attributable to the complexity, uncertainties, and ever-emerging knowledge about environmental issues.

Critically, anthropologists recognise the time-consuming nature of relationship building and learning approaches, and that this is about more than merely 'consulting'; building trust through transparency in the process, being honest about anticipated outcomes, and seeking opportunity for stakeholders to have input into the process of programme development are vital.

Anthropologists working in the field of biosecurity (Collier, Lakoff and Rabinow 2004) have articulated a framework for 'problematisation' of the factors that have led to biosecurity being perceived and acted on in particular ways. Following Foucault, these writers stress that problematisation cannot rest at the level of dissecting pre-existing criteria since something earlier 'must have happened to introduce uncertainty, a loss of familiarity: that loss, that uncertainty is the result of difficulties in our previous way of understanding, acting, 
relating' (Foucault, 1994:598, in Collier et al., 2004:3). Related to biosecurity, Collier et al. (2004) explore questions such as:

What kind of 'uncertainty' or 'loss of familiarity' has been introduced by the threat of bioterrorism, and in what domains? What ways of understandings, acting and relating are disrupted? What forms of political analysis, moral reflection and techno-scientific practice are being mobilized by actors (scientists, policy-makers, planners) in shaping - and operating in relationship to - something called biosecurity? (2004:3).

This has particular relevance for analysis of social learning related to LIUDD, since the observation has been made that new technologies are more likely to be taken up when they do not contradict people's 'self-definitions and takenfor-granted relationships to each other and to their landscapes' (Greider and Garkovich, 1994:7).

As Greider and Garkovich point out:

Social impacts occur from the points of inception and, especially, announcement of the planned change....If, however, the development project or environmental change cannot be incorporated into these everyday lifeworlds or threatens access to valued resources, then negotiations among members of the group about who they were, who they are, and who they hope to be at this place and in this space will occur. These new definitions are the sociocultural impacts (1994:14-15, italics in original).

The issue of facilitating interdisciplinary research is a crucial and broad-ranging issue beyond the scope of this paper. It is important to acknowledge here, however, that the environmental anthropologist's role of 'cultural translator' can exist between different science disciplines as well as between the researchers and the wider public (Strang, 2005). Anthropologists have stressed a need to negotiate a role that moves beyond being the 'people experts' or the 'helpers' in environmental research agendas dominated by engineers, physicists and economists (Nader, 2006, Henning, 2005). Laura Nader has advocated the importance of 'studying up' (Nader, 1972), that is, studying the experts and critiquing the processes through which science and technology are developed (Nader, 2004). Nader has put this approach to work in a long-term engagement in issues related to energy, publishing predominantly in biophysical science forums rather than anthropological (e.g. 1980, 1981). 
The empirical nature of ethnographic research, developed through fieldwork in specific contexts, provides potential for collaboration with some natural sciences that also rely upon context-specific data collection (Head et al., 2004). Both natural and social sciences can develop fine-grained, context-specific data that cannot necessarily be generalised to broader contexts but can provide detailed knowledge and understandings for contrast and comparisons with other contexts.

Different time scales in research present a challenge to interdisciplinary research, however; because social science generally involves diverse types of data it often takes much longer to collate and analyse such a wide range of data (Strang, 2005). Outputs from social science can also be difficult to mesh with outputs from the physical sciences, particularly in contexts where brevity is prioritised. Strang recommends science teams develop 'a range of outputs that reflect the needs and qualities of each of the disciplines involved, and consider how these inform and support each other' (2005:13).

This paper now turns more specifically to the LIUDD programme, and issues identified in the early stages of the research programme which limit implementation of LIUDD.

\section{LOW IMPACT URBAN DESIGN AND DEVELOPMENT}

Auckland grows at a rate of 49 people and 21 houses per day (Auckland Regional Council, 2003), and the population is projected to reach 1.8 million by 2026 (Statistics NZ, 2006). Rapid urban growth is putting pressure on natural resources and on the physical infrastructure. Conventional approaches to urban development - earth working and compacting large areas, piping streams and filling in gullies, together with the increased imperviousness in urban areas - are resulting in serious environmental impacts. Contaminants and sediment are reducing water quality and damaging streams and estuaries, and excessive peak stream flows are leading to degradation and erosion of stream courses. Low-impact approaches have the potential to reduce environmental impacts by slowing and filtering storm-water before it reaches waterways, and ultimately, coastal areas.

LIUDD employs designs and development practices that use natural systems and new low-impact technologies to avoid, minimize, and mitigate environmental damage (Newman and Kenworthy, 1999). Key elements include limiting impervious surfaces and earthworks, using vegetation to assist in trapping pollutants and sediment, and enhancing biodiversity. Design features 
- including rain gardens, swales, and riparian strips - can reduce storm-water run-off and improve water quality.

Internationally, LIUDD initiatives are fairly new, although demonstration developments and aspects of LIUDD are emerging in many cities (van Roon and Knight, 2004). In New Zealand, few examples of LIUDD exist. While some district and city councils advocate a low-impact design approach to urban development to reduce adverse environmental impacts, implementation depends on the willingness and ability of stakeholders to embrace principles of LIUDD, and on planning and regulatory processes that incorporate integration across council policies, plans, and codes of practice. Our interviews with council staff, developers and consultants in 2004 and 2006 indicated that these conditions are not yet in place.

The Council planner who commented that changing the way urban environmental management occurs is like 'trying to turn a supertanker round' was not far off the mark. Storm-water management, in particular, has long been considered solely an engineering issue, dealt with by experts. The suggestion that on-site, smaller scale options may result in improved environmental outcomes is one that challenges this dominant approach. As Nader noted in relation to energy, the dominant thinking is that 'large scale system-centred complex technologies are more likely to spread the good life than small scale man-centred technologies' (2004:773). The anthropologist's task includes examining these taken-for-granted assumptions.

Similarly, in relation to urban development, conventional 'hard' engineering approaches (e.g. kerb and channelling, piping, paving) are often seen as signifying progress, a demarcation of the 'urban' from the 'rural', and providing the 'obvious' and 'guaranteed' solution to dealing with storm-water. The rapidly declining health of our waterways as a result of these conventional approaches is seldom called into question. On the one hand, councils are aware that urban dwellers expect traditional forms of infrastructure such as kerbs, channels and extensive pavements, which reinforce current investment patterns of councils. On the other hand, residents have an expectation that streams and beaches be kept pristine (Auckland Regional Council, 2000) and that there will be an increase in the number of native birds and fish in streams (Heremaia, 2001, Eason, 2003). Simple, small-scale devices and approaches (e.g. rain gardens, road-side swales, revegetation) can produce improved results but require a major shift in the way stakeholders perceive storm-water management; in the first instance, a shift from its being perceived as solely 'Council business'. 
Early in the research programme, we undertook interviews with a range of development professionals and local and regional council staff (31 people in total) to develop an understanding of the context in which development was taking place in Auckland and to identify the barriers and contributing factors to the implementation of LIUDD. Interviews were semi-structured. The barriers to implementation that we identified included a lack of integrated policy, plans and practices which supported the implementation of LIUDD. This lack of integration led to considerable time delays in consent processes, which became a further deterrent to the implementation of LIUDD by developers. Some council and developers were also unwilling to consider these new technological approaches, some because of a lack of certainty around technical and environmental performance of low impact approaches, and others because there were no financial incentives to do so. People had differing views on which environmental issues needed prioritising, and some perceived there was a mismatch between LIUDD and compact growth (housing intensification) goals.

Developers made a resounding call for greater integration of policy, plans and practices to support the implementation of LIUDD. Conflicting requirements of planners and roading and storm-water engineers within councils was a common complaint:

...there is actually a conflict within the council themselves. They don't have a consistent overarching policy where they say, yes, we will encourage developers to provide innovative storm-water. But they might say that in their rules but when push comes to shove, they want the most simplistic uninnovative storm water system, they want the most sort of simplistic unexperimental sort of roading layouts, because they keep saying we have to take them over, we have to maintain them at the end of the day (Developer).

...At the moment we've got the [council] storm water people saying we want low-impact design options...then we go to a different department, transportation have now told us to widen all footpaths from 1.5 metres wide to 1.8 so there's a complete lack of integration in consistency of policy. There are very mixed messages coming from Council (Consultant).

Concerns about responsibility for and costs of on-going maintenance of onsite devices were an important issue. Lack of certainty about new technical approaches and liability issues also underpinned much of the conflict. For 
example, one consultant, responsible for getting consents through Council, explained how inconsistencies within a Council around the new technology plays out:

...we had an interesting situation with a [developer]...We had a specific yield [of storm-water] that needed to be established [driven by Council]...we went through the consent process, went rather smoothly because we did what they wanted, because the yield [was right] - used some innovative storm water management approaches, got the consent, got the contractors moving, then things starting coming off the caboose, shall we say. We went for engineering approval. Hang on, would not accept rain gardens, would not accept permeable pavement roads, so the consent that had gone in and got approved on the low-impact design basis got thrown out and we ended up with a conventional subdivision with a swale on the road frontage which doesn't work but there's a swale nevertheless.. Council weren't prepared to accept the liability if the road may fail.

WOULD IT HAVE WORKED DO YOU THINK?

No....concerns were expressed internally and the council engineers came to their own assumptions so it was pointless two engineers trying to do something that they both knew at heart wasn't going to work. So we've got a concrete nibbed asphalt road (Consultant)

In contrast, council planners expressed frustration that developers tended to be fixed on the 'bottom line' in terms of regulations, quality, and money rather than looking to improve standards and implement low-impact approaches.

... at the moment the culture is very much the law says this is what we've got to do and as far as we're concerned, the government looks after us and if they say it's okay, it's got to be okay, we're not going to be seen to go above it (Council, consents).

At the beginning of the LIUDD programme, it was anticipated that infrastructural costs would be reduced by implementing low-impact approaches. To date this has not been the experience within the development industry, largely because the technology is fairly new and much is still to be learned about successful implementation. This is leading councils to take conservative approaches in most cases. Greater certainty about the economic, technical and ecological efficiency is vital before any real traction can be gained, as this 
consultant explains:

Our experience to date has been that the low-impact design implementation has added significantly to costs without any real cost benefit analysis being undertaken by anyone. We at the moment are experiencing some developments where Council is saying we want you to implement some low impact design options but we don't have enough competence in it ourselves to think that it's going to work, so we want you to do conventional engineering as well, so it's a doubling up of cost and ultimately that has to be passed on to the end-user (Consultant).

Developers commonly stated that it was finally easier to use conventional approaches to avoid huge time delays and costs in gaining Council consents:

...we attempt to attenuate, for example, our own storm-water, and we will have ponds or whatever other devices, and we get absolutely bloody hammered by the council, they just keep lifting the bar and lifting the bar...all the time on the standards. You never get agreement - there is no sort of standard design for a storm-water pond other than what the ARC [Auckland Regional Council] comes up with, and the council always wants double what the ARC wants ... and I have actually got to the point now where I think bugger it, I am just going to pay them the money. If they want $\$ 5000$ a lot for storm-water, and I give them the money, and I have got a 50-lot subdivision, and I give them a big fat cheque, and at the end of the day I can push that storm-water to the boundary of the subdivision then into the river it goes...it is a totally wrong attitude, but you get so frustrated trying to do the right thing (Developer).

We try and do some fairly innovative things in either commercial or residential, and by doing more innovative things, the way that the regulatory framework is set up... is that if you do anything slightly innovative that doesn't fully comply with all the rules, you go into a different pile over here and getting consents is a hell of a lot harder (Developer).

There was a general lack of agreement on what leads to best environmental outcomes and which 'low impact' approaches need to be prioritised. The development industry generally expressed frustration at the regional council's hands-off approach to managing waterways. 
...generally in broad acre development the landscape... the land has been used for farming for the previous 100 [years]... What is basically left is... remnant creek systems that are extremely polluted... [we are told] for goodness sake don't touch the creek system 'cos you are not allowed to because that is the policy (Consultant).

Developers objected to being painted as the 'bad guys' in relation to urban environmental management and cited some examples where they felt the regional council had got it seriously wrong:

...I went out yesterday to have a look at 3 or 4 [storm water ponds]... I came away disgusted because... a couple of the ponds being built which were absolutely filthy...the process of filtration is not even working and you have a creek system no more than 20 metres away which was the most heavily polluted creek system I have ever seen where some developers had to build a culvert across - at a cost of hundreds of thousands of dollars - to protect the stream....and underneath, the stream has died because it doesn't see any natural sunlight. Well my granny could have told you that it was going to die!

Based on a catchment-level approach to the protection of water quality and wildlife, regulators focused on prohibiting interference with existing waterways and on limiting earthworks to reduce sediment loads. As this Auckland Regional Council person stated, earthworks were extensive across the region:

...we get about 1000-1200 hectares of earthworks a year...Most of those earthworks are associated with developments of some sort... Most of those developments are conventional developments so it's a standard 4-500 square metre sections...So the entire site is earth worked and the entire site is going to end up with houses on it, so what we're doing is we're trying to influence the way that development occurs...so you only developed land that is suitable to be developed [in terms of gradient] (Council, consent).

In the view of some participants, low-impact approaches were incompatible with local government's desire for higher density housing. Councils were prioritising intensification over these low-impact approaches by limiting greenfields development:

...if you focus on storm water...the risk is that you tend to spread urban development out...now we're adding swales...lots of perme- 
able surfaces, and that tends to spread things out and has people living in little clusters around contours...you don't go anywhere near the gullies or the water course. So when people need to go to school or the shops or something they get in their four-wheel drive and drive off there...So there's that sort of tension between intensification, which we're quite committed to, and the storm water impacts, which we're also committed to. But somehow you have to integrate the two (Council, policy).

This research indicated a fundamental mismatch in the discourses of two key professional stakeholder groups - governance and industry sectors - about how LIUDD is to be achieved. While both groups were interested in achieving more sustainable outcomes in urban development, they tended to prioritise different features of LIUDD and focused their efforts at different spatial scales.

Some councils were working to support improved approaches to storm-water management, but struggled to integrate these approaches with those that support compact growth. Council planners tended to prioritise intensification of development as a means of improving regional environmental outcomes. This focus is a result of an international trend towards compact settlement forms, incorporated into the Auckland Regional Growth Strategy and related planning documents that required local councils to encourage intensification. Limiting sprawl was seen as a key issue to retain the urban green fringe, accommodate growth and reduce environmental degradation. Enforcing the metropolitan urban limit, educating the public on the benefits of higher density living, and improving the capacity of infrastructure to allow intensification were seen as key to these aims.

Not surprisingly, developers' focus was on what would sell, with some focused on 'low impact' approaches, including creating attractive neighbourhoods through revegetation and the provision of generous parks and recreational spaces that created linked and walkable community spaces. Some developers also focused on innovative management of storm-water to improve environmental outcomes, based on awareness of international trends towards low-impact storm water management. Developers said the key issue to be addressed was the inconsistencies in policy in relation to low-impact stormwater management, and the willingness and capacity of councils to process associated consents in a timely way. 
Low-impact approaches to urban environmental management are still fairly new, meaning that no one group can claim to be experts. The building of knowledge and capacity at all levels is therefore vital. LIUDD requires responsibility for urban environmental management to be broadened beyond the expert sphere.

Identification of barriers to the uptake and implementation of LIUDD is a starting point, but in itself is of limited value. More useful is to recognise the multiple and often competing perceptions of how sustainable urban environmental management can be achieved and to look for opportunities for improved processes, experimental research, and information sharing within the multiplicity of factors that shape outcomes (Guy and Marvin, 1999). Case studies and learning groups are a means to do this.

People within the development industry and councils indicated that they would value the opportunity to share learning, including sharing the successes in the planning and implementation of LIUDD. Case studies, currently being developed in two parts of Auckland, therefore have a focus on 'What's working?' Case studies provide the basis for developing relationships and engaging stakeholders in the collaborative learning approach of the programme.

Anthropologists working in applied settings in relation to environmental issues have commented on their marginalized position within the discipline (e.g. Stonich, 1999, Nader, 2006), but have nevertheless persisted and made meaningful contributions to complex environment issues. We acknowledge that ethnography has long been used as an agent of social change (see, for example, Joan Metge's article, this issue). In this science programme, the anthropologist moves beyond ethnography - or perhaps more accurately builds on ethnographic research - to facilitate a process of learning, experimentation and reorganization to address environmental issues.

We are using ethnographic process to inform both the content and practices of the LIUDD research programme. The anthropologist is influencing the research design and processes by operating as a 'cultural translator.' Through this role she is creating forums for stakeholders (including science colleagues) to engage in a learning process. Grounded theorising occurs through this learning process. Continued engagement with anthropologists based in universities connects the anthropologist and her research to broader theoretical developments and to support from others working in the discipline of anthropology. 
The collaborative learning approach utilising ethnographic research methods seeks to engage researchers as well as other stakeholders in processes of critical reflection. These processes have the potential to reframe urban development 'problems' through an appreciation of the multiple values and assumptions that shape these problems. This approach to research presents challenges and opportunities for engaging a multidisciplinary team in inter- and trans-disciplinary research. Reflection on that learning process is core to our work and provides fruitful ground for analysis to be presented in future papers.

\section{ACKNOWLEDGEMENTS}

Our sincere thanks to Jeff Sissons and Michael Krausse for their valuable comments on an earlier draft of this paper.

\section{REFERENCES}

Agar, M. 1996. The Professional Stranger: An Informal Introduction to Ethnography (2nd ed). New York: Academic Press.

Allen, W.J., Bosch, O.J.H., Gibson, R.G., and Jopp, A.J. 1998. 'Co-learning our way to sustainability: An integrated and community-based research approach to support natural resource management decision making. In Multiple Objective Decision Making for Land, Water and Environmental Management. S.A. El-Swaify and D.S. Yakowitz, (Eds.), Boston: Lewis Publishers: 51-59.

Auckland Regional Council, 2003. A Day in the Life of Auckland Regional Council.

Auckland Regional Council, 200o. Low-impact Design Manual for the Auckland Region. Technical Publication 124, Auckland: Auckland Regional Council.

Austin, D. E. 2004. 'Partnerships, Not Projects! Improving the Environment Through Collaborative Research and Action', Human Organization, 63 (4): 419-430.

Barr, A. 1991. Practising Community Development: Experience in Strathclyde. London: Community Development Foundation.

Barr, A., Hamilton, R. and Purcell, R. 1996. Learning for Change: Community Education and Community Development. London: Community Development Foundation. 
Bernard, H. 1988. Research Methods in Cultural Anthropology. Newbury Park: Sage.

Brosius, J. P. 1999. 'Analyses and Interventions: Anthropological Engagements with Environmentalism', Current Anthropology, 40 (3): 277-309.

Collier, S.J., Lakoff, A. and Rabinow, P. 2004. 'Biosecurity: Towards an Anthropology of the Contemporary', Anthropology Today, 20 (5):3-7.

Dalmau, T. and Dick, B. 1990. Managing Transition: A Key to Creating Effective Learning Environments, Chapel Hill, Qld: Interchange.

Douglas, M. and Wildavsky, A. 1983. Risk and Culture: An Essay on the Selection of Technological and Environmental Dangers, Berkeley: University of California Press.

Eason, C. 2003. 'LIUDD: Making it Mainstream' Proposal 8193-ASCI-LCR, Initial FRST Bid.

Ellen, R., (ed.) 1984. Ethnographic Research: A Guide to General Conduct, London: Academic Press.

Greenaway, A., Allen, W., Feeney, C., Heslop, V. 2006. 'Learning into a Low-impact Future: Collaborative Approaches to Storm-water Management', NZ Water and Wastes Association Conference on Storm-water Management, Royal Lakeside Novotel, Rotorua, 4-5 May 2006.

Greider, T. and Garkovich, L. 1994. 'Landscapes: The Social Construction of Nature and the Environment', Rural Sociology, 59 (1):1-24.

Guy, S. and Marvin, S. 1999. 'Understanding Sustainable Cities: Competing Urban Futures', European Urban and Regional Studies, 6 (3):268-275.

Head, L., Trigger, D. and Woodward, E. 2004. 'Nature, Culture and the Challenges of Environmental Sustainability: Bridging the Science/Humanities Divide'. Report on ARC Research Network Special Initiative seed funding. http://www.uow.edu.au/research/rso/grants/outcomes/external/reports/ lhead/

Henning, A. 2005. 'Climate Change and Energy Use: The Role of Anthropological Research', Anthropology Today, 21 (3): 8-12. 
Heremaia, C. 2001. Education Strategy Waterways and Wetlands: Ko te Aratohu Poipoi e whai ake ki te Matauranga a Nga Arawai Repo, Christchurch: Christchurch City Council.

Johnston, B. 1994. 'Human Rights and the Environment', Practicing Anthropology, $16(1): 8-12$.

Keen, M., Brown, V., and Dyball, R. 2005. Social Learning in Environmental Management: Building a Sustainable Future, London: Earthscan.

Laverack, G. and Labonte, R. 2001. 'Capacity Building in Health Promotion, Part 1: For Whom? And for what Purpose?', Critical Public Health, 11 (2): $110-127$.

LIUDD website: http://www.landcareresearch.co.nz/research/urban/liudd/

Marcus, G. E. 2005. 'The Passion of Anthropology in the U.S., Circa 2004', Anthropological Quarterly, 78 (3): 673-695.

Melrose, M.J. 2001. 'Maximizing the Rigor of Action Research: Why Would You Want To? How Could You?' Field Methods, 13 (2):160-18o.

Mulcock, J., Pocock, C. and Toussaint, Y. 2005. 'Introduction: Current Directions in Australian Anthropologies of the Environment', The Australian Journal of Anthropology, 16 (3): 281-293.

Nader, L. 1972. 'Up the Anthropologist: Perspectives Gained from Studying Up', In D.H. Hymes, (Ed.) Reinventing Anthropology, New York: Pantheon Books: 284-311.

Nader, L. 1980. Energy Choices in a Democratic Society, Washington: DC American Academy of Arts and Sciences.

Nader, L. 1981. 'Barriers to Thinking New about Energy', Physics Today, 34 (3): 9, 99-102.

Nader, L. 2004. 'The Harder Path: Shifting Gears', Anthropological Quarterly, 77 (4): 721-791.

Nader, L. 2006. 'Rediscovering Energy Issues', Anthropology Today, 22 (2): 22. 
Newman, P., and Kenworthy, J. 1999. Sustainability and Cities, Washington, D.C: Island Press.

Scott, K, Park, J. and Cocklin, C. 200o. 'From 'Sustainable Rural Communities' to 'Social Sustainability': Giving Voice to Diversity in Mangakahia Valley, New Zealand', Journal of Rural Studies, 16: 433-446.

Statistics NZ, March 2006. 'Auckland Region Quarterly Review', http://arc.govt.nz/arc/auckland-region/statistics/

Stonich, S. C. 1999. 'Comments' on J. P. Brosius, 'Analyses and Interventions:Anthropological Engagements with Environmentalism', Current Anthropology, 40 (3): $277-309$.

Strang, V. 2005. 'Integrating the Social and Natural Sciences in Environmental Research: A Discussion Paper' (under review), University of Queensland Workshop, October 2004.

Stringer, E. 1999. Action Research, Washington, D.C: Sage Publications.

Van Roon, M.R., Greenaway, A., Dixon, J. and Eason, C. 2006. New Zealand Low Impact Urban Design and Development Programme: scope, founding principles and collaborative learning. Paper for the Urban Drainage Modelling and Water Sensitive Urban Design Conference, Melbourne, April 2006.

Van Roon, M.R. and Knight, S. J. 2004. Ecological Context of Development: NewZealand Perspectives, Auckland, N.Z.: Oxford University Press.

Van Roon, M. and van Roon, H. 2005. 'Low Impact Urban Design and Development Principles for Assessment of Planning, Policy and Development Outcomes: A Working Paper of the Centre for Urban Ecosystem Sustainability' (University of Auckland and Landcare Research Ltd).

Wallace, M. 2004. 'Low Impact Design: Is it the Land Developers' Nemesis? An Auckland Region Perspective'. Water \& Waste in New Zealand, July 2004: 34-40.

Wilhite, H. 2005. 'Rediscovering Energy Issues', Anthropology Today, 21 (3):1-2. 